\title{
Sobre espaço público e heterotopia
}

\author{
Rodrigo Ramos Hospodar Felippe Valverde ${ }^{*}$
}

\section{Resumo}

O objetivo desse artigo é traçar um paralelo entre a crise no modelo utópico de espaço público e a eminência de novas formas, comportamentos e significados dos espaços urbanos, que podem ser mais precisamente compreendidos à luz da idéia de heterotopia. Este conceito problemático de Foucault foi debatido no contexto da geografia pós-moderna e, nesse artigo, é utilizado para se questionar o papel da dimensão social dentro da teoria dos espaços públicos.

Palavras-chave: Heterotopia; Espaço público; Foucault.

\section{On public space and heterotopy}

\begin{abstract}
The aim of this article is to establish a reflection oposing the so-called crisis in the utopian model of public space and the imminence of new forms, meanings and behaviors in urban spaces, which can be more accurately understood with the idea of heterotopy. This problematic concept of Foucault was discussed in the context of post-modern geography and, in this article, is used to question the role of the social dimension within the theory of public spaces.
\end{abstract}

Key words: Heterotopy; Public space; Foucault.

* Professor Doutor do Departamento de Geografia da USP (rvalverde@usp.br).

Geosul, Florianópolis, v. 24, n. 48, p 7-26, jul./dez. 2009 
VALVERDE, R.R.H.F. Sobre espaço público e heterotopia.

Neste artigo, traçaremos um paralelo entre a crise no modelo utópico de espaço público, tal qual este foi abordado na Geografia, e a eminência de novas formas, comportamentos e significados dos espaços urbanos, que podem ser mais precisamente compreendidos à luz da idéia de heterotopia.

Não tomamos o espaço público aqui nem como um espaço em crise, nem como uma utopia inexistente: seus valores, seus significados e suas formas são analisados a partir do resultado da interação entre diferentes atores sociais, objetos espaciais e significados. Pretendemos analisar o espaço público, suas formas, os comportamentos que têm lugar em seu interior e os seus significados múltiplos a partir da prerrogativa de que as dinâmicas sócio-espaciais que aí se desenrolam são condicionadas pela teoria geral, mas também conferem sentidos a esta última. É dentro desse quadro analítico que apresentamos aqui a idéia de heterotopia como uma alternativa de estudo dos espaços públicos na Geografia.

Para avançar nesse sentido, iremos primeiramente apresentar a idéia de Foucault e a sua transposição para a Geografia, ressaltando as adaptações que foram feitas nesse processo. Em seguida, veremos que tipo de contribuições à noção de heterotopia pode oferecer à discussão de espaço público ao retirar a sua carga teleológica.

\section{A origem e definição da idéia de heterotopia}

A origem da idéia de heterotopia remete à concepção de espaço desenvolvida por Foucault, em especial aquela encontrada no texto "Des espaces autres", de 1967, e no livro "Les Mots et les choses", de 1966. O autor apresentava uma abordagem espacial que conferia uma interpretação plural da sociedade, levando em conta atores e fenômenos que anteriormente seriam descartados devido ao seu caráter marginal, inconstante e apolítico.

É justamente nesse sentido que o autor opôs tempo e espaço. $\mathrm{O}$ espaço de Foucault foi relacionado ao dinamismo social, às mudanças, aos confrontos de idéias e à eminência de novas representações. O tempo, por sua vez, estaria atrelado à 
VALVERDE, R.R.H.F. Sobre espaço público e heterotopia.

consolidação de significados e de narrativas, ganhando valor com a estabilidade, com a permanência dos arranjos de poder, com a associação a uma identidade dominante. Nas palavras de Foucault:

"L'époque actuelle serait peut-être plutôt l'époque de l'espace. Nous sommes à l'époque du simultané, nous sommes à l'époque de la juxtaposition, à l'époque du proche et du lointain, du côté à côté, du disperse. Nous sommes à un moment où le monde s'éprouve, je crois, moins comme une grande vie qui se developperait à travers le temps que comme un réseau qui relie des points et qui entrecroise son écheveau" (FOUCAULT, 2001: 1571) ${ }^{1}$.

Foucault parecia acreditar que a transformação da sociedade Moderna não seria possível simplesmente através da troca de idéias realizada nos fóruns políticos pré-determinados, mas sim pela visibilidade que o espaço provia a necessidades e sentimentos que eram combatidos pelo Estado. É a partir desse princípio que o autor acrescentou que a sociedade contemporânea ainda lida com o espaço de modo rígido, como se as suas formas e significados fossem consensuais. Nas palavras do autor:

“(...) je crois que l'inquietude d'aujourd'hui concerne fondamentalement l'espace (...) l'espace contemporain n'est peut-être pas encore entièrement désacralisé (...). Et peu-être notre vie est-elle encore commandée par un certain nombre d'oppositions auxquelles on ne peut pas toucher, auxquelles l'instituition et la pratique n'ont pas encore osé porter atteinte: des oppositions que nous admettons comme toutes donnés: par exemple, entre l'espace privé et l'espace public, entre l'espace de la famille et l'espace social, entre

${ }^{1}$ Tradução: “A época atual será talvez, sobretudo, a época do espaço. Nós estamos na época do simultâneo, nós estamos na época da justaposição, na época do próximo e do distante, do lado a lado, do disperso. Nós estamos em um momento no qual o mundo se faz sentir, creio eu, menos como uma grande vida que se desenvolverá através dos tempos do que como uma rede que liga pontos e que entrecruza seus laços" (FOUCAULT, 2001: 1571). 
VALVERDE, R.R.H.F. Sobre espaço público e heterotopia.

l'espace culturel et l'espace utile, entre l'espace de loisirs et l'espace de travail (...)"2 (FOUCAULT, 2001:1573).

Entre as oposições, destacamos a presença da noção de espaço público, que ainda se encontraria parcialmente "sacralizada". O autor se referia às resistências das ciências sociais em admitir que os seus princípios, os seus objetos, os seus arranjos e os seus atores poderiam mudar. Foucault ainda deixou entender que a quebra dessa resistência seria relevante para a definição de uma relação entre Estado e sociedade que não seria baseada no controle.

Com isso, o autor apresentou interesse pela idéia de heterotopia ao procurar uma forma de classificação espacial que valorizava a presença de múltiplas representações conflitantes em uma mesma área. Para Foucault, existiriam certos espaços que, devido à concentração de atores e de significados, seriam caracterizados pela inversão, suspensão ou neutralização da ordem oficial:

"Mais ce qui m'interesse, ce sont, parmi tous ces emplacements, certains d'entre eux qui ont la curieuse propriété d'être en rapport avec tous les autres emplacements, mais sur un mode tel qu'ils suspendent, neutralisent ou inversent l'ensemble des rapports qui se trouvent, par eux, désignés, reflétés ou réfléchis" (FOUCAULT, 2001: 1574) ${ }^{3}$.

2 Tradução: “(...) eu acredito que a inquietude de hoje concerne fundamentalmente ao espaço (...) o espaço contemporâneo não está ainda inteiramente 'dessacralizado'(...). E talvez nossas vidas ainda estejam comandadas por um certo número de oposições que não podemos tocar, as quais a instituição e a prática ainda não ousaram atingir: oposições que nós admitimos como dadas, por exemplo, entre o espaço privado e o espaço público, entre o espaço da família e o espaço social, entre o espaço cultural e o espaço útil, entre o espaço de lazer e o espaço de trabalho (...)" (FOUCAULT, 2001: 1573).

3 Tradução: "Mas os que me interessam entre todos os lugares são aqueles que possuem a curiosa propriedade de estar em relação com todos os outros lugares, mas de um modo tal que eles suspendem, neutralizam ou invertem o conjunto de relações que se acham designados e refletidos por eles" (FOUCAULT, 2001: 1574). 
VALVERDE, R.R.H.F. Sobre espaço público e heterotopia.

$\mathrm{O}$ autor complementou esse raciocínio colocando a heterotopia como o inverso da idéia de utopia. Se Foucault definia a utopia como um "espaço irreal" (imaterial) que perpassa todos os outros, promovendo um arranjo harmônico, a heterotopia, por sua vez, seria um espaço concreto no qual todas as representações se encontrariam presentes, causando contestações, fragmentações e inversões de regras devido aos seus conflitos. Segundo Foucault:

“ (...) des lieux réels, des lieux effectifs, des lieux qui sont dessinés dans l'institution même de la société, et qui sont des sortes de contre-emplacements, sortes d'utopies effectivement réalisées dans lesquelles les emplacements réels, tous les autres emplacements réels que l'on peut trouver à l'interieur de la culture sont à la fois représentés, contestés et inversés, des sortes de lieux qui sont hors de tous les lieux, bien que pourtant ils soient effectivement localisables. Ces lieux, parce qu'ils sont absolument autres que tous les emplacements qu'ils reflètent et dont ils parlent, je les appelerai, par opposition aux utopies, les hétérotopies" (FOUCAULT, 2001: 1574-1575) ${ }^{4}$.

Para Foucault, tais "espaços outros" seriam "localizáveis", mas estariam fora de todas as outras espacialidades. $\mathrm{O}$ autor se referia ao fato de que nem o poder público nem outro ator são capazes de definir um arranjo coeso para o espaço heterotópico. Tal tipo de espaço seria marcado por superposições de espacialidades e por dinâmicas competitivas que se sucedem no

4 Tradução: "lugares reais, lugares efetivos, lugares que foram desenhados pela própria instituição da sociedade, e que são tipos de contra-localizações, tipos de utopias efetivamente realizadas dentro das quais as localizações reais, todas as outras localizações reais que se pode achar no interior da cultura são simultaneamente representadas, contestadas e invertidas, tipos de lugares que se encontram fora de todos os lugares, ainda que, entretanto, eles sejam efetivamente localizáveis. Esses lugares, como são absolutamente outros do que todas as localizações que eles refletem e das quais eles falam, eu os chamarei, em oposição às utopias, as heterotopias" (FOUCAULT, 2001: 1574-1575). 
VALVERDE, R.R.H.F. Sobre espaço público e heterotopia.

tempo. Dessa forma, o espaço heterotópico não seria reduzido à questão da dominação e da influência que se associa ao debate da territorialidade.

Um outro sinal dessa ausência de relações claras e duradouras de dominância que podem ser observadas na idéia de heterotopia está relacionado à desconstrução do discurso que sustenta e justifica a organização espacial. Segundo Foucault, a heterotopia impediria o ato de nomear um determinado objeto, o que necessariamente definiria uma relação de poder. Em suas palavras:

“Les hétérotopies inquiètent (...) parce qu'elles minent secrètement le langage, parce qu'elles empêchent de nommer ceci et cela, parce qu'elles brisent les noms communs ou les enchevêtrent, parce qu'elles ruinent d'avance la 'syntaxe', et pas seulement celle qui construit les phrases, - celle (...) qui fait 'tenir ensemble' (...) les mots et les choses" (FOUCAULT, 1966: 9) . $^{5}$

Ao fazê-lo, Foucault destacava que a heterotopia causaria efeitos não apenas sobre a ordem pública ou sobre um grupo dominante: esse tipo de espaço causaria uma sensação de desconforto a todos aqueles que o vivenciam. Porém, Foucault destaca que o espaço heterotópico continuaria a ser freqüentado pelos indivíduos na medida em que sacia algum tipo de necessidade. Com isso, Foucault julgava positivo o papel das heterotopias para a renovação social, ainda que não ocorresse de forma ordenada:

"L'espace dans lequel nous vivons, par lequel nous sommes attirés hors de nous-mêmes, dans lequel se déroule

\footnotetext{
5 Tradução: “As heterotopias geram inquietação (...) porque elas minam secretamente a linguagem, porque elas impedem a nomeação disto ou daquilo, porque elas quebram os nomes comuns ou os misturam desordenadamente, porque elas arruínam antes de tudo a 'sintaxe', e não apenas aquela que constrói as frases - mas sim aquela (...) que 'mantém em conjunto' (...) as palavras e as coisas" (FOUCAULT, 1966: 9).
} 
VALVERDE, R.R.H.F. Sobre espaço público e heterotopia.

précisement l'erosion de notre vie, de notre temps et de notre histoire, cet espace qui nous ronge et nous ravine est en luimême aussi un espace hétérogene. Autrement dit, nous ne vivons pas dans une sorte de vide, à l'intérieur duquel on pourrait situer des individus et des choses. Nous ne vivons pas à l'intérieur d'un vide qui se colorerait de différents chatoiements, nous vivons à l'intérieur d'un ensemble de relations qui définissent des emplacements irréductibles les uns aux autres" (FOUCAULT, 2001: 1573-1574) ${ }^{6}$.

A entropia presente em tal espaço nos sinalizaria uma inadequação entre a maneira que imaginamos e utilizamos os espaços e as suas funções e seus sentidos originais. Procurariam-se os pontos de instabilidade da vida social moderna, apontando necessariamente para mudanças, contradições e inversões da relação fundamental entre território e cidadania. As heterotopias se constituiriam em espaços nos quais as memórias política e institucional não se apresentariam, em espaços nos quais as classificações funcionais não se aplicariam, em espaços nos quais as regras de convivência não são baseadas na civilidade.

Porém, a idéia de heterotopia de Foucault não teve a repercussão esperada devido à falta de clareza nos seus princípios básicos e nos exemplos. A heterotopia da biblioteca, do cemitério, da caserna, do asilo e da feira, entre outras, foram criticadas pela incapacidade de se exprimirem satisfatoriamente através do resumo de idéias relacionadas. A insistência de Foucault no uso de metáforas para orientar a reflexão espacial e do poder diminuía o poder explicativo da idéia. Afinal, em que medida uma biblioteca

\footnotetext{
${ }^{6}$ Tradução: "O espaço no qual nós vivemos, pelo qual nós somos atraídos para fora de nós mesmos, no qual se desenrola precisamente a erosão de nossa vida, de nosso tempo e de nossa história, esse espaço que nos corrói e nos marca é também um espaço heterogêneo. Dito de outra forma, nós não vivemos dentro de um tipo de vazio, no interior do qual se poderia situar os indivíduos e as coisas. Nós não vivemos no interior de um vazio que se coloriria de diferentes luzes refletidas, nós vivemos no interior de um conjunto de relações que definem localizações irredutiveis frente às outras" (FOUCAULT, 2001: 1573-1574).
} 
VALVERDE, R.R.H.F. Sobre espaço público e heterotopia.

seria um espaço "totalmente externo a todos os outros"? Por que tal espaço "não poderia ser nomeado" e como se poderia estudar um objeto que não pode ser identificado? Por que nossas vidas seriam "erodidas" pelo contato com um tal espaço? E de que modo esse espaço "inverte, suspende, transforma ou nega a ordem"?

Foi com o desdobramento das críticas pós-modernas que a idéia de heterotopia foi recuperada e vem ganhando maior interesse. É deste ponto que parte o interesse geográfico pela abordagem espacial de Foucault e mais especificamente pela idéia de heterotopia.

\section{A abordagem geográfica da idéia de heterotopia}

$\mathrm{Na}$ última década, diversos geógrafos demonstraram interesse em comentar e interpretar a idéia de heterotopia para criticar os limites da geografia moderna. Relph, por exemplo, define a idéia de heterotopia como:

“(...) a space in which the drawing of definite centres, boundaries, and regularities is impossible. (...) that is to say it is pluralistic, chaotic, designed in detail yet lacking universal foundations or principles, continually changing, linked by centreless flows of information. (...) it is marked by deep social inequalities. It renders doubtful most of the conventional ways of thinking about landscapes and geogaphical patterns" (RELPH, 1991: 104-105) ${ }^{7}$.

Harvey, por sua vez, criticou essa idéia em suas obras, pois, para o autor, tais "espaços de resistência e de liberdade" seriam por demais fugazes, e teriam como preço a desconstrução da

7 Tradução: “(...) espaço no qual é impossivel o desenho de centros, fronteiras e regularidades precisas. (...) é plural, caótica, desenhada em detalhes ainda que não possua fundações ou princípios universais, mudando continuamente, ligada por fluxos de informação sem centralidade. (...) está marcada por profundas desigualdades sociais. Torna duvidosa a maior parte dos modos convencionais de pensar as paisagens e os modelos geográficos" (RELPH, 1991: 104-105). 
VALVERDE, R.R.H.F. Sobre espaço público e heterotopia.

Modernidade. Harvey reafirmaria um compromisso da Geografia com a ordem institucional ao argumentar que a lógica espacial do conceito de heterotopia não traria nada de positivo para a reorganização social. Em suas palavras, o conceito de heterotopia:

“ (...) presumes that connections to the dominant social order are or can be severed, attenuated or, as in prision, totally inverted. The presumption is that power/knowledge is or can be dispersed and fragmented into spaces of difference. It presumes that whatever happens in such spaces of 'otherness' is of interest and even in some sense 'acepptable' or 'appropriate'. (...) What appears at first sight as so open by virtue of its multiplicity suddenly appears either as banal (...) or as a more sinister fragmentation of spaces that are closed, exclusionary, and even threatening within a more comprehensive dialectics of historical and geographical transformation. The concept of heterotopia has the virtue of insisting upon a better understanding of the heterogeneity of space but it gives no clue as to what a more spatiotemporal utopianism might look like. Foucault challenges and helps destabilize (...) but provides no clue as to how any kind of alternative might be constructed" (HARVEY, 2000: 184-185) ${ }^{8}$.

8 Tradução: "Tal conceito presume que conexões com a ordem social dominante podem ou são rompidas, atenuadas ou, como na prisão, totalmente invertidas. A presunção é que poder/conhecimento podem ser dispersos e fragmentados em espaços da diferença. Presume que, seja lá o que acontece em tais espaços de 'alteridade', é de interesse e, em certo sentido, é até mesmo 'aceitável' ou 'apropriado'. (...) O que parece ser a primeira vista tão aberto por sua virtude ou multiplicidade repentinamente parece como banal (...) ou como uma fragmentação mais sombria de espaços que são fechados, exclusivos, e até ameaçadores dentro de uma dialética mais inclusiva da transformação histórica e geográfica. O conceito de heterotopia tem a virtude de insistir sobre uma melhor compreensão da heterogeneidade do espaço, mas não dá pistas sobre o que um utopismo espaço-temporal deve parecer. Foucault desafia e ajuda desestabilizar (...) mas não dá evidências de como qualquer tipo de alternativa deve ser construída" (HARVEY, 2000: 184-185). 
VALVERDE, R.R.H.F. Sobre espaço público e heterotopia.

Nesse contexto, Harvey avalia que a contribuição de uma reflexão sobre a ordem espacial deve ser condicionada pela sua possibilidade de aplicação à estrutura social, ou ao menos a uma teoria que possa ser relacionada a essa última. A idéia de heterotopia seria então descartada devido as suas pequenas possibilidades de se converter em uma ferramenta para a política.

De modo contrário, as obras de Soja e Gregory chamaram atenção para o papel que os espaços heterotópicos cumpriam na superação do olhar moderno do espaço urbano. A heterotopia se constituiria em espaços de resistência às diversas formas da racionalidade instrumental moderna. Segundo Soja, a heterotopia seria:

“(...) part of the pressupositions of social life. He [Foucault] saw them as 'something like counter sites' (...) in which real sites, all the other real sites that can be found within the culture are simultaneously represented, contested, and inverted. (...) These curious sites are socially constructed but they simultaneously recreate and reveal the meaning of social being. Conventional formal descriptions of them (...) tend to miss their meaning, hide the revealing tensions and contradictions that exist between them and all other sites" (SOJA, 1995: 14) .

De acordo com Soja, o espaço heterotópico não pode ser dissociado dos significados e representações sociais que ali se desenvolvem, se constituindo em um conjunto de relações espaciais concretas e imateriais. Em suas palavras:

"O espaço heterogêneo e relacional das heterotopias de Foucault não é nem um vazio desprovido de substância, a

\footnotetext{
${ }^{9}$ Tradução: “(...) parte de pressupostos da vida social. Ele [Foucault] as via como 'algo como contralocalidade' (...) nas quais todas as outras localidades reais que poderiam ser encontradas na cultura são simultaneamente representadas, contestadas e invertidas. (...) Essas localidades curiosas são socialmente construídas, mas simultaneamente recriam e revelam o significado da existência social. Descrições formais convencionais dessas heterotopias (...) tendem a perder os seus significados, esconder as tensões e contradições reveladoras que existem entre elas e todas as outras localidades" (SOJA, 1995: 14).
} 
VALVERDE, R.R.H.F. Sobre espaço público e heterotopia.

ser preenchido pela intuição cognitiva, nem um repositório de formas físicas a ser fenomenologicamente descrito em toda a sua resplandecente variabilidade. Trata-se de um espaço outro, (...) a espacialidade efetivamente vivida $e$ socialmente criada, simultaneamente concreta e abstrata, a contextura das práticas sociais. É um espaço raramente visto, pois tem sido obscurecido por uma visão bifocal que, tradicionalmente, encara o espaço como um constructo mental ou como uma forma física" (SOJA, 1993: 26).

Para Soja, a natureza de um espaço heterotópico deve ser expressa a partir da maneira pela qual formas, comportamentos e significados se combinam de modo atípico para formar uma espacialidade distinta daquelas previstas pela lei e pelos hábitos politicamente aceitos. $\mathrm{O}$ autor argumenta que a idéia de heterotopia aponta para mais do que uma unidade espacial concreta, fechada e com funções sociais bem definidas. Soja defende que a heterotopia poderia ser transposta para as reflexões do ordenamento espacial, do planejamento urbano e das representações sócio-espaciais.

É preciso dizer que, segundo Foucault, tal interpretação de Soja seria um tanto quanto problemática, uma vez que a idéia da heterotopia residiria em algo que deveria fugir da normalidade, do convencional, do regrado e do cotidiano. De acordo com Foucault, as heterotopias ocorreriam quase sempre em espaços fechados, para garantir um certo grau de isolamento que afaste a possibilidade do controle social por parte do Estado. Nessa linha de raciocínio, o espaço público seria, via de regra, o oposto da heterotopia, ou seja, uma utopia que não se alcança jamais.

Porém, Soja argumenta que a crise dos espaços públicos da atualidade está relacionada à fraqueza dos fóruns institucionais de renovação social, salientando que outros padrões de produção espacial surgiriam para substituir os antigos. Assim, a cidade moderna é o pano de fundo apresentado por Soja para o estudo da heterotopia como fenômeno de erosão das relações sócio-espaciais. De acordo com o autor, a eminência do Estado Moderno haveria diminuído significativamente o papel dos espaços urbanos como mediadores da política. Soja avalia que, nesse processo, seria 
VALVERDE, R.R.H.F. Sobre espaço público e heterotopia.

aberto caminho para uma transformação do espaço urbano e das representações que aí têm lugar, que ganhariam novos sentidos e novas forças. Nas palavras do autor:

"In the modern world, the primary scale of surveillance and adherence, of citizenship and politics, shifted dramatically from the city to the state, recentering the locus of power outside the direct gaze of the citadels and into a more invisible process of 'normalization' that pervades patriotic allegiance and representative rather than participatory democracy. It is no surprise then to find modern political theory and critical social science abandoning its roots in the polis and denying the specificity of the city, its centrally as an object of knowledge. The discourse on power and knowledge in the constitution of society continues to acknowledge that things took place in cities (an unavoidable though inconsequential coincidence) but were not (or no longer) of the cities, directly imbricated in the urban" (SOJA, 1995: 29) ${ }^{10}$.

Soja afirma que o espaço público teria sido em grande parte dissociado das representações sociais, fato que se tornou ainda mais notável uma vez que o ordenamento espacial da Modernidade se caracterizava por separações funcionais. Com isso, Soja sugere que as relações entre política, cidadania e espaço urbano teriam se distanciado das manifestações da sociedade. Progressivamente,

10 Tradução: "No mundo moderno, a escala primária de vigilância e aderência, de cidadania e política, mudou dramaticamente da cidade para o Estado, re-centrando o lócus do poder fora do olhar direto das cidadelas e mais no processo invisível de 'normalização' que permeia o devotamento patriótico e a democracia representativa, ao invés da democracia participativa. Não é surpresa então descobrir que a teoria política moderna e ciência social crítica estão abandonando suas raízes na polis e negando a especificidade da cidade, sua centralidade como objeto de conhecimento. $O$ discurso sobre poder e conhecimento para a constituição da sociedade continua a reconhecer que as coisas tomam lugar na cidade (uma coincidência inevitável, mas sem conseqüências), mas não eram (ou não mais) das cidades, diretamente imbricadas com o urbano" (SOJA, 1995: 29). 
VALVERDE, R.R.H.F. Sobre espaço público e heterotopia.

Estado e sociedade teriam desenvolvido as suas dinâmicas em direções opostas, e não em sentido convergente. Devido a isto, o autor afirma que os espaços públicos vêm sendo invadidos por representações sócio-territoriais. A multiplicação dessas representações geraria novos significados para o espaço público, que passaria a ser visto como fonte de insegurança. $\mathrm{O}$ desconforto causado pela vivência desse espaço seria derivado da heterogeneidade social que aí tem lugar e de um ceticismo em relação à política institucional.

Soja acredita que a aceleração do tempo e a criação de mecanismos para controlá-lo vêm gerando as condições ideais para o aparecimento de novas heterotopias: a tentativa de estabelecer um ritmo da vida que pudesse ser avaliado simplesmente por uma posição no espaço e pelo seu comportamento previsto no planejamento geraria então contradições, sentimentos e demandas que iriam, em grande parte, contra a própria expressão deste controle. Desses focos de instabilidade e de insurgência, emergiriam tanto os movimentos políticos formais, quanto uma série de localidades que tomam sentidos através dos seus usos sociais não-regulados, e, por último, certos estabelecimentos públicos de controle do que é convencionado como desviante.

Acreditamos que a idéia de heterotopia pode ser mais inovadora frente à noção de espaço público na medida em que fosse avaliada através de atores, elementos e objetos diferentes dos usualmente encontrados. Veremos no próximo item como a idéia de heterotopia estabelece um contraponto à idéia de espaço público.

\section{Repensando a relação entre espaço público e heterotopia}

Um espaço público pode ser avaliado através da idéia de heterotopia na medida em que certas cidades apresentam localidades que não se caracterizam pela coordenação entre Estado e sociedade em prol do ordenamento político, ou por um conjunto de ações políticas sistemáticas de atores sociais em busca de uma maior visibilidade de seus interesses. Isso significa que ausência da 
VALVERDE, R.R.H.F. Sobre espaço público e heterotopia.

finalidade política na noção de espaço público afeta diretamente a natureza das formas, dos comportamentos e dos significados.

Em primeiro lugar, se estabelece uma relação de oposição entre: a cidadania, que prevê direitos e deveres definidos por instituições públicas para servir todos os cidadãos que se encontrarem dentro do mesmo recorte espacial; e o padrão relacional, que aposta em um arranjo informal constituído por diferentes indivíduos e espaços que depende exclusivamente da interação, definindo avanços e recuos de direitos e deveres de acordo com as circunstâncias.

A segunda oposição que pode ser analisada entre a noção de espaço público e a idéia de heterotopia que defendemos aqui pode ser explicada pela definição de suas funções. Todo espaço público possui como origem e finalidade a construção do fato político, por mais que as suas dinâmicas não apresentem importância direta para a administração pública ou que a sua simbologia não remeta a um interesse coletivo. Tais espaços são normatizados por leis, têm equipamentos que lhes foram emprestados pelo Estado, e têm um papel definido dentro de um plano de ação estatal.

O modo pelo qual o espaço heterotópico pode ser qualificado em uma perspectiva funcional destaca a sua ligação com a esfera social. A heterotopia se liga a manifestações de interesses que não podem ser qualificados como políticos e que se orientam por relações de troca. Dessa forma, o que estaria em jogo em um espaço heterotópico é o saciamento de um interesse, de um desejo ou de uma necessidade de determinados atores através da reorganização constante do espaço, ainda que outros sejam prejudicados por esse novo arranjo informal.

A terceira oposição diz respeito ao grau de controle nas mudanças da morfologia urbana. A normatividade, o interesse político e o controle social exercidos pelo Estado sobre o espaço público exigem um conjunto de formalidades e justificativas para mudar. A viabilidade técnica, o interesse coletivo, os custos, a conveniência da obra são considerados antes que qualquer projeto tenha permissão para prosseguir. No contexto de um espaço heterotópico, no entanto, a 
VALVERDE, R.R.H.F. Sobre espaço público e heterotopia.

omissão do Estado, a flexibilização de suas leis e a violação das normas públicas permitem que a morfologia urbana seja mais facilmente alterada, ainda que em caráter provisório.

A quarta oposição coloca o padrão de interação social em destaque. No caso do espaço público, a civilidade é o modelo de interação. Espera-se de cada cidadão o comportamento cordial e moral quando encontra os seus pares. A partir do cumprimento das normas de conduta, o espaço público deveria ganhar estabilidade e limitar os conflitos. As formas e equipamentos de tal espaço supostamente qualificariam e estimulariam a civilidade.

No que tange ao padrão de interação social de um espaço heterotópico, é a territorialidade que definiria o modo pelo qual os indivíduos interagem, através de estratégias para controlar ou influenciar a organização espacial. As propriedades e equipamentos de um espaço público são usados para justificar a apropriação por parte de certos atores e para condicionar as trocas. No entanto, o espaço heterotópico não é caracterizado por relações estáveis de dominância, impedindo que as territorialidades se exprimam através de relações de exclusividade.

A quinta oposição se refere aquilo que os atores sociais exigem dos espaços públicos e das heterotopias. Os atores que vivenciam o espaço público e conferem sentido as suas dinâmicas procuram garantir as condições ideais para o desdobramento dos princípios democráticos que orientam as suas leis e teorias. Tal procura se traduz através da luta contra as barreiras de acesso às áreas públicas e a favor da igualdade de condições entre os diversos atores. É preciso ressaltar que o espaço público comporta diversas outras características. Porém, é através dessas iniciativas que os seus atores tentam pressionar o sistema institucional a incorporar novos elementos, de acordo com os limites da teoria clássica.

Por sua vez, são sensivelmente diferentes os termos que definem a busca realizada pelos atores em um espaço heterotópico. Tratam-se de estratégias variadas para neutralizar e flexibilizar a ordem pública a fim de obter ganhos individuais ou grupais. O que se procura com a busca é estabelecer barreiras e zonas de controle 
VALVERDE, R.R.H.F. Sobre espaço público e heterotopia.

que possibilitem a exploração informal da visibilidade pública. Tenta-se estabelecer uma dinâmica não-regulada pelo poder público, ganhando assim maior flexibilidade para mudar sem precisar prestar contas continuamente. Portanto, a formalização institucional não é o objetivo da vivência de uma heterotopia, pois transferiria o poder de produzir o espaço novamente para o Estado.

O sexto par que antagoniza o espaço público e a heterotopia está relacionado à maneira pela qual se define a relação entre espaço e tempo. Enquanto o espaço público se caracteriza nesse sentido pelo planejamento urbano e pela prospectiva, a heterotopia se orienta pela ação não planejada e pela vida cotidiana. Em outras palavras, de um lado, os atores que elaboram as leis e as funções do espaço público procuram observar os seus objetos, os seus atores e o seu papel para a cidade no intuito de elaborar politicamente certas prioridades de investimento. Assim, o ordenamento de um espaço público é condicionado em parte pela sustentabilidade e o interesse coletivo em manter esse arranjo no futuro.

Por outro lado, o espaço heterotópico não apresenta essa preocupação com a sustentabilidade ou com a durabilidade dos seus arranjos de ordem. Admite-se largamente que todo e qualquer arranjo que se desenrola nesse espaço é temporário. A heterotopia também não se traduz em um olhar para o futuro, como realizam os planejadores do espaço público. Todo esforço em definir arranjos espaciais é voltado para suprir elementos à vida cotidiana, ainda que tais arranjos se concretizem em detrimento de um equilíbrio em relação aos atores ou a ordem pública.

A oposição seguinte deixa claro que aquilo que é valorizado com a definição de um espaço público é uma ordem que engendra a justiça social, e, com o aparecimento de um espaço heterotópico, o que ganha maior valor é a liberdade que permite o acesso e a autoregulamentação. No primeiro caso, admite-se que o Estado possa limitar a liberdade de usos dos espaços no intuito de garantir uma relação equilibrada e sustentável entre os atores. No segundo caso, os atores sociais ganham maior destaque, uma vez que têm 
VALVERDE, R.R.H.F. Sobre espaço público e heterotopia.

mais liberdade para estabelecer arranjos de ordem que se sucedem no espaço, ainda que não possuam continuidade.

A penúltima oposição em destaque deixa evidente outra diferença essencial entre o espaço público e o espaço heterotópico: os seus mecanismos de renovação. O espaço público é renovado a partir do momento em que as representações sociais fazem apelo às instituições políticas para que essas tomem posição diante de um determinado assunto. É o sistema político formal e suas instituições que funcionam como canais de renovação, por mais que uma parte significativa das aspirações surja através da interação de atores no espaço concreto. Nesse processo, as novas demandas sociais perdem invariavelmente uma parte do seu poder transformador para serem incorporadas ao código jurídico.

O espaço heterotópico, por sua vez, encontra o seu poder de renovação nos sucessivos arranjos informais de organização sócioespacial. Esse tipo de espaço prescinde da mediação político-social oferecida pelas instituições formais, se renovando continuamente a partir das estratégias que cada indivíduo ou grupo social exerce. Ainda que o poder público muitas vezes tente reprimir esse canal informal de renovação sócio-espacial, os espaços heterotópicos se desenvolvem a margem da política.

A última oposição presente no quadro comparativo relaciona o espaço público à utopia e a liga a heterotopia à distopia. Na utopia dos espaços públicos, existiria uma metanarrativa que reuniria uma infinidade de relatos. Esses relatos não seriam mutuamente excludentes e se encaixariam dentro de uma estrutura maior, que seria comum a todos os indivíduos. Os espaços públicos seguiriam a forma sugerida por essa meta-narrativa, apresentando através de manifestações públicas ocasionais novas demandas sociais de grande apelo popular e compatíveis com o interesse coletivo.

O espaço heterotópico seria marcado por uma distopia. Esta distopia do espaço heterotópico não se aplica apenas em situações autoritárias, uma vez que a forte presença do grupo dominante reprimiria mais fortemente as manifestações informais. No caso da distopia de um espaço heterotópico, emergiriam diversas narrativas 
VALVERDE, R.R.H.F. Sobre espaço público e heterotopia.

que competem entre si e com a meta-narrativa dominante, questionando o ordenamento existente. $\mathrm{O}$ desdobramento dessa situação para o espaço público seria uma diminuição do seu poder de coesão e da política institucional.

Em resumo, nossa classificação de um espaço como heterotópico se desenvolveria na medida em que Estado e sociedade se encontram em oposição no que tange a definição de parâmetros que regulamentam o seu uso. Mais especificamente, esse tipo de espaço seria possível quando um determinado espaço público que concentra muitos atores, narrativas e objetos passa a apresentar uma configuração espacial que se renova continuamente e através de canais informais.

Nesse espaço heterotópico, os atores sociais não estariam preocupados em formalizar as suas demandas através de instituições públicas, uma vez que essa mediação incide em custos e limites que podem comprometer a liberdade adquirida. Com isso, o jogo das representações tende a protelar, dividir e questionar qualquer iniciativa pública formal para retomar as rédeas do controle social.

No espaço heterotópico, é a interação dos atores combinada com formas e significados relativos ao espaço que permite a definição, os seus efeitos variam de caso a caso. De uma forma geral, pode-se afirmar que: por um lado, a heterotopia impede que a ordem pública evolua através da sua renovação, da incorporação de novos atores, da politização e da eficiência nas políticas públicas; e que, por outro lado, a heterotopia estimula a autoregulação do espaço e, portanto, a autoconsciência dos seus atores.

Essa afirmação não deve ser confundida com a maneira pela qual a perspectiva republicana dos espaços públicos aponta para uma deterioração da vida pública que deve ser combatida. Também não deve ser diretamente associada com o modo pelo qual a geografia marxista interpreta as novas manifestações de grupos étnicos e identitários como ações políticas que almejam a transformação radical das relações de poder. Essas linhas de argumentação estão concentradas no poder político, em sua estrutura, em suas instituições, em seus recursos, em seus 
VALVERDE, R.R.H.F. Sobre espaço público e heterotopia.

equipamentos e em seus atores, fazendo com que a defesa e mudança de seus valores sejam observadas unicamente como matérias de interesse institucional.

O funcionamento de um espaço heterotópico sinaliza o afastamento dessa lógica. Quando se argumenta que a heterotopia bloqueia os mecanismos formais de renovação política, aquilo que está sendo avaliado não é uma ação consciente de natureza política em prol de um objetivo único. Também não se defende que um grupo deva exercer os seus recursos para substituir o papel do Estado como regulador da sociedade. A heterotopia exige a presença de múltiplos atores, que podem ou não assumir o papel de mediadores, desde que essa seja feita informalmente e temporariamente. Dessa forma, quando se argumenta que os atores sociais ganham maior consciência de si mesmos e promovem uma auto-regulação, deixa-se claro que o que está em jogo são as necessidades de cada um dos atores, e não um interesse coletivo.

Normalmente, os efeitos e aplicações sobre o espaço público que estão associados a uma dinâmica heterotópica podem ser resumidos na seguinte relação: a) admite o estudo de múltiplas espacialidades sobre um mesmo recorte espacial, evitando a repetição de estudos relacionados à territorialização de um grupo social, ou à análise geral da estrutura espacial da política; b) confere sentido a manifestações que anteriormente eram apenas classificadas como deteriorações da publicidade clássica; c) chama atenção para a espacialidade da esfera social, ao invés de reificar continuamente a política institucional; d) diminui o caráter teleológico que orienta o debate usual da publicidade, promovendo relatos renovados; e) salienta o papel da visibilidade no espaço para integrar atores marginalizados pela sociedade; f) avalia o espaço público, ao associá-lo a presença e a relevância de cada um de seus princípios nos espaços concretos como uma tendência à transformação.

\section{Referências bibliográficas}

FOUCAULT, M. “Des espaces autres". In: Dits e Écrits, tome 2: 1976-1988. Paris: Gallimard, 2001. pp.1571-1581. 
VALVERDE, R.R.H.F. Sobre espaço público e heterotopia.

FOUCAULT, M. Les mots et les choses. Paris: Gallimard, 1966.

GENOCCHIO, B. "Discourse, discontinuity, difference: the question of 'Other' spaces” In: WATSON, S. e GIBSON, K. (ed.). Postmodern cities and spaces. Oxford: Blackwell, 1995.

GREGORY, D. Geographical Imaginations. Cambridge: Basil Blackwell, 1994.

HARVEY, D. Spaces of Hope. Los Angeles: University of California Press, 2000.

LUSSAULT, M. \& STASZAK, J.F.“Hétérotopie”. In: LÉVY, J. \& LUSSAULT, M. (dir). Dictionnaire de la Géographie et de l'espace des sociétés. Paris: Belin, 2003. pp. 452-453.

PHILO, C. "Foucault's geography" In: Environment and Planning D - Society and Space volume 10, 1992. pp. 137-161.

RELPH, E. "Post-modern geography". In: The Canadian Geographer, v.35, n¹, 1991. pp. 98-105.

SOJA, E. Postmetropolis - Critical studies of cities and regions. Oxford: Blackwell, 2000.

SOJA, E. "Heterotopologies: a remembrance of other spaces in the citadel of L.A." In: WATSON, S. e GIBSON, K. (ed.). Postmodern cities and spaces. Oxford: Blackwell, 1995.

SOJA, Edward. Geografias Pós-Modernas. Rio de Janeiro: Jorge Zahar, 1993.

VALVERDE, R.R.H.F. A transformação da noção de espaço público: a tendência à heterotopia no Largo da Carioca. Tese de Doutorado em Geografia/UFRJ, 2007. 